\title{
Artmış overbite'a sahip iskeletsel sınıf 1 ve 2 anomalili erişkin bireylerin değerlendirilmesi; bölüm 1: kraniyofasiyal morfoloji
}

\author{
Fatma Deniz Uzuner, ${ }^{*}$ Belma Işık Aslan, \\ Müfide Dinçer \\ Ortodonti Anabilim Dalı, Gazi Üniversitesi Diş Hekimliği \\ Fakültesi Ankara, Türkiye
}

\section{ÖZET}

AmAÇ: İskeletsel Sınıf 1 ve 2 anomali ile birlikte artmış overbite'a sahip erişkinlerde kraniyofasiyal morfolojiyi değerlendirmek ve cinsiyet bakımından karşılaştırmaktır.

GEREÇ VE YÖNTEM: Ortodontik tedaviye alınmış, artmış overbite'a ( $\geq 4.5 \mathrm{~mm}$ ) sahip 16-45 yaşları arasındaki 188 (75 erkek, 113 kız) bireye ait lateral sefalometrik film değerlendirildi. Örneklem 3 gruba ayrıldı: Grup $1(n=87)$ iskeletsel Sınıf 1 (ANB=0-4), Grup $2(n=64)$ iskeletsel Sınıf 2 (ANB $\geq 4.5$ ), dişsel Sınıf II/1 ve Grup $3(n=37)$ iskeletsel Sınıf 2, dişsel Sınıf II/2 malokuzyona sahip bireyler. Gruplar cinsiyetlere göre karşılaştırıldı. Beş açısal, sekiz doğrusal ölçüm yapılarak kraniyofasiyal yapılar sagital ve vertikal yönde değerlendirildi. Elde edilen verilerin istatistiksel değerlendirmesinde Bonferroni düzeltmeli ANOVA testi, Mann-Whitney U testi ve Kruskal-Wallis testi kullanıldı. Ayrıca, overbite ile GoGnSN değeri arasındaki korelasyon değerlendirildi.

BULGULAR: Grup 1 ve 2'de milimetrik ölçümlerde erkeklerin kızlardan daha büyük değerlere sahip olduğu belirlendi. Her iki cinsiyette; SNB değerinin Grup 1 ve 2 arasında anlamlı farklılık gösterdiği, SN/GoGn değerinin Grup 2'de anlamlı seviyede yüksek olduğu bulundu. Tüm gruplarda SN/GoGn ile overbite arasında negatif korelasyon saptandı. ANS-SN (mm) değeri ve üst yüz yüksekliğinin (NANS; $\mathrm{mm}$ ) yalnız erkeklerde Grup 2'de artmış olduğu ve Grup 1 ve Grup 3 ile anlamlı farklılık gösterdiği saptandı.

Sonuç: Grup 1 ve 3'te kraniyofasiyal yapıların sagital ve vertikal yönde benzerlik gösterdiği bulunurken; Grup 2'de sagital yönde mandibulanın daha geride konumlandığı, vertikal yön boyutlarının ise artmış olduğu tespit edildi.

ANAHTAR Kelimeler: Artmış overbite; kraniyofasiyal morfoloji; maloklüzyon, angle sınıf I; maloklüzyon, angle sınıf II bölüm 1; maloklüzyon, angle sınıf II bölüm 2

Makale gönderiliş tarihi: 16 Mart 2015; Yayına kabul tarihi: 09 Nisan 2015 *iletişim: Fatma Deniz Uzuner, Gazi Üniversitesi Diş Hekimliği Fakültesi, Ortodonti Anabilim Dalı, 06510 Emek, Ankara, Türkiye;

e-posta: fduzuner@yahoo.com.tr
Kaynak Göstermek İçin: Uzuner FD, Aslan BI, Dinöer M. Artmış overbite'a sahip iskeletsel sınıf 1 ve 2 anomalili erişkin bireylerin değerlendirilmesi; bölüm 1: kraniyofasiyal morfoloji. Acta Odontol Turc 2015;32(3):116-22.

YAYIN HAKKI: () 2015 Uzuner ve ark. Bu eserin yayın hakkı Creative Commons Attribution License ile ruhsatlandırılmıştır. Sınırsız kullanım, dağıtım ve her türlü ortamda çoğaltım, yazarlar ve kaynağın belirtilmesi kaydıyla serbesttir.

[Abstract in English is at the end of the manuscript]

\section{Giriş}

Artmış overbite ortodontik tedaviler içinde başarılı sonuçların elde edilmesinde zorlanılan anomaliler arasındadır. Sıklıkla maksilla ve mandibulanın antero posterior yöndeki anomalileriyle birlikte ortaya çıkmaktadır. ${ }^{1,2}$ Farklı sagital ve vertikal yöndeki anomalilerle beraber gözlenebilen artmış overbite'ın tedavi planlamasında bu farklı iskeletsel morfolojinin karakteristik özellikleri değerlendirilmelidir. ${ }^{3}$

Derin kapanış anteroposterior yöndeki iskeletsel sapmalarla birlikte görüldüğünde erken daimi dişlenme döneminde fonksiyonel ve/veya ağızdışı aygıtların kullanımı hem sagittal sapmayı önlemek hem de kapanışı açmak için idealdir.4-6 İlerleyen yaşla bireyin kraniofasiyal yapısında modifikasyonlar gözlenmektedir. Büyüme ve gelişimle birlikte kraniyofasiyal yapıda gözlenen bu değişimlerde mandibulanın geç dönem büyüme atakları ${ }^{7}$ ve rotasyon modelinin de büyük etkisi vardır. ${ }^{8}$ Dolayısıyla büyüme ve gelişimi devam eden bireylerde bahsedilen etkenlerin devreye girmesiyle arzu edilen iskeletsel ve dental düzelme elde edilebilmektedir.

Puberteden sonra ise; kalan büyüme potansiyeli bu problemin düzelmesine izin vermeyeceğinden tedavi planlamasında ortognatik cerrahi ve ortodontik kamuflaj tedavi alternatifleri söz konusu olacaktır., 4,9,10 Sadece dental hareketler ile vertikal anomalinin kompanze edilip edilmeyeceğine karar verilmelidir. Bu tip vakalarda doğru teşhis ve tedavideki uygun mekaniklerin tasarımı vakalardaki iskeletsel ve dişsel kaynakların detaylı ayırımı ile mümkün olmaktadır. 
Literatürde dental okluzyon ile kraniofasiyal morfoloji ilişkisini değerlendiren pek çok çalışmaya rastlanmaktadır.,11-15 Overbite ile kraniyofasiyal morfoloji ilişkisini değerlendiren çalışmalarda çelişkili sonuçlar bildirilmektedir. ${ }^{14,16-18}$ Bu farklılıklar araştırma materyallerinin oluşturulması sırasında (bireylerin yaşı, sayısı, etnik yapısı, çalışma grubunun seçim kriterleri) ve kullanılan sefalometrik noktalar ve istatistik yöntemindeki farklılıklara bağlı olabilmektedir. Yapılan çalışmalarda daha fazlasıyla büyüme ve gelişimi devam eden bireylerin değerlendirildiği, yaş ayırımı yapılmayıp her yaş grubunu içerdiği ve çoğunda cinsiyetlerin ayrı ayrı değerlendirilmemiş olduğu gözlenmektedir. ${ }^{4,13,16,19,20}$

Derin kapanış ilişkisini inceleyen çalışmalarda çoğunlukla Sınıf II/2 malokluzyona sahip bireylerin değerlendirildiği görülmektedir.5,11,12,16,21 Sınıf II/2 bireylerin genel olarak Sınıf 1 normal kapanışlı veya Sınıf II/1 olgularla overbite kriteri aranmaksızın openbite, normal ve derin kapanışlı bireylerin ayrımı yapılmaksızın karşılaştırıldığı görülmektedir. ${ }^{19,20,22,23}$ Ayrıca, Sınıf II/2 bireylerin değerlendirildiği çalışmalarda iskeletsel yönden Sınıf 1 ve Sınıf 2 ayırımının yapılmadığı sadece dişsel sınıflamanın seçim kriteri olarak kullanıldığı görülmektedir. Literatürde artmış overbite ile birlikte sagital yönde farklı iskeletsel malformasyona sahip bireylerde karşılaştırma yapan çalışmaya rastlanılmamaktadır.

Bu araştırmanın amacı iskeletsel Sınıf 1 ve 2 anomali ile birlikte artmış overbite'a sahip erişkin bireylerde kraniyofasiyal morfolojiyi değerlendirmek ve cinsiyet bakımından karşılaştırmaktır.

\section{Gereç Ve Yöntem}

Ortodonti kliniğinde tedaviye alınmış, artmış overbite'ın $(\geq 4.5 \mathrm{~mm}$ ) olduğu iskeletsel Sınıf $1(\mathrm{ANB}=0-4)$ ve Sınf 2 (ANB $\geq 4.5)$, anomaliye sahip 16-45 yaşları arasındaki erişkin bireylere ait tedavi başlangıcı lateral sefalometrik filmler ve klinik kayıt formları değerlendirmeye alındı. Çalışmaya dahil olma kriterleri; bireylerin daha önce ortodontik veya protetik tedavi görmemiş olması, şiddetli kraniyofasiyal anomali bulunmaması, tüm daimi dişlerinin ağız içinde sürmüş olması (yirmi yaş dişleri hariç), aktif büyüme ve gelişimin tamamlanmış olması, servikal vertebral gelişiminin faz 6 'da olması ${ }^{24}$ şeklinde belirlendi. Sonuç olarak 188 erişkin bireye (75 erkek, 113 kız) ait kayıtlar değerlendirmeye alındı.

Örneklem 3 gruba ayrıldı: Grup $1(n=87)$ iskeletsel Sınıf I (ANB=0-4), Grup $2(n=64)$ iskeletsel Sınıf 2, dişsel Angle Sınıf II/1 (ANB $\geq 4.5)$ ve Grup $3(n=37)$ iskeletsel Sınıf 2, dişsel Sınıf II/2 malokuzyona sahip bireyler. Sınıf II/ 2 ve II/1 belirlenmesinde British Standard Institue'un belirttiği kriter baz alındı; ${ }^{25}$ üst kesicilerin retrokline olduğu alt kesicilerin üst kesicilerin singulumunun gerisinde kaldığı overjetin artmamış olduğu bireyler Sınıf II/
2 olarak ve üst kesicilerin proklinasyon gösterdiği, overjetin $4.5 \mathrm{~mm}$ den fazla olduğu bireyler Sınıf II/1 olarak sınıflandırıldı. Gruplar cinsiyetlere göre karşılaştıııldı.

Lateral sefalometrik filmler doğal baş konumunda, dudaklar istirahatte ve dişler maksimum interkuspidasyonda iken alınmıştır. Farklı magnifikasyonda çekilen lateral sefalometrik filmler 1:1 oranında olacak şekilde standardize edildi. Filmler üzerinde beş açısal, sekiz doğrusal ölçüm yapılarak kraniyofasiyal yapılar sagital ve vertikal yönde değerlendirildi (Şekil 1).

Çizim ve ölçüm hatasının belirlenmesi amacıyla rastgele seçilen 40 lateral sefalometrik film 2 hafta sonra tekrar çizildi ve ölçümler yapıldı. Ölçüm tekrarlama katsayıları güvenilir sınırda bulundu ( $r=0.91-0.94)$.

\section{İstatistiksel değerlendirmeler}

İstatistiksel değerlendirmeler SPSS for Windows programı (15.0, Chicago, IL, ABD) kullanılarak yapıldı. Ölçümleri yapılan değişkenlerin normal dağılım gösterip göstermediği Kolmogorov-Smirnov testi ile belirlendi. Normal dağılım gösteren değişkenlerde gruplar arası farklılıkların değerlendirilmesinde Bonferroni düzeltmeli ANOVA testi, normal dağılım gözlenmeyen değişkenlerin gruplar arası farklılıkların değerlendirilmesinde Bonferroni düzeltmeli Kruskal-Wallis testi ve ikili karşılaştırmalarda Mann-Whitney U testleri kullanıldı. Ayrıca, overbite ve SN/GoGn arasında korelasyon değerlendirildi. İstatistiksel anlamlılık seviyesi $p<0.05$ olarak belirlendi.

\section{BULGULAR}

Cinsiyetlere göre grup içi karşılaştırmalar Tablo 1'de gösterildi. Grup 1 ve 2'de milimetrik ölçümlerde erkeklerin kızlardan önemli seviyede daha büyük değerlere

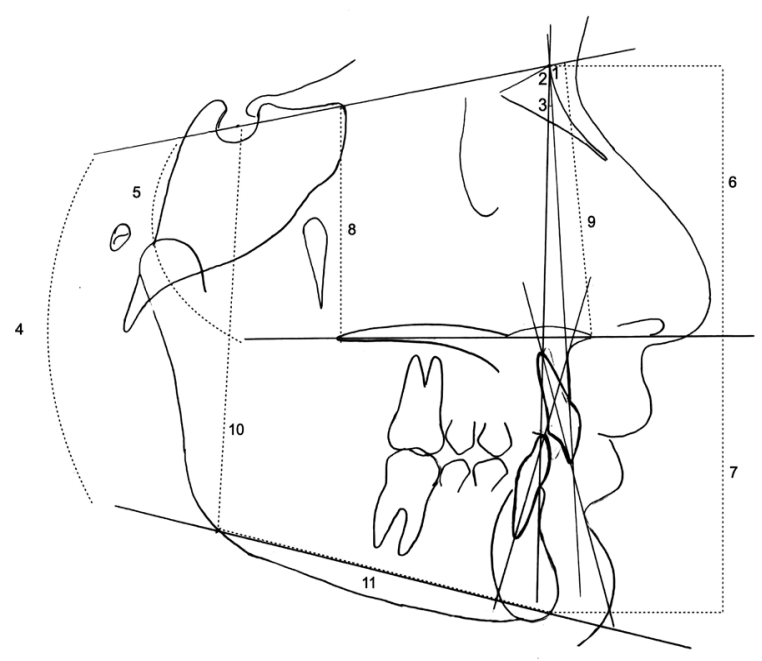

Şekil 1. Sefalometrik film üzerinde yapılan açısal ve doğrusal ölçümler; 1: SNA, 2: SNB, 3: ANB, 4: SN/GoGN, 5: SN/PP, 6: N-ANS, 7: ANS-Gn, 8: PNS-SN, 9: ANS-SN, 10: S-Go, 11: Go-Gn 
Tablo 1. Ölçüm değerlerinin cinsiyetler arası karşılaştırı|ması

\begin{tabular}{|c|c|c|c|c|c|c|c|c|c|}
\hline & \multicolumn{3}{|c|}{ Grup 1} & \multicolumn{3}{|c|}{ Grup 2} & \multicolumn{3}{|c|}{ Grup 3} \\
\hline & Kızlar $(n=56)$ & Erkekler $(n=31)$ & $p$ değeri & Kızlar $(n=39)$ & Erkekler $(n=25)$ & $\mathrm{p}$ değeri & Kızlar (n=18) & Erkekler $(n=19)$ & $\mathrm{p}$ değeri \\
\hline SNA ( $\left(^{\circ}\right) P$ & $80.23 \pm 3.55$ & $80.52 \pm 3.45$ & 0.71 & $80.68 \pm 3.24$ & $81.28 \pm 3.92$ & 0.51 & $82.58 \pm 2.32$ & $81.37 \pm 3.63$ & 0.23 \\
\hline SNB $\left({ }^{\circ}\right) P$ & $77.43 \pm 3.56$ & $78.15 \pm 3.56$ & 0.36 & $75.14 \pm 3.59$ & $75.36 \pm 3.58$ & 0.81 & $77.19 \pm 2.31$ & $76.39 \pm 3.85$ & 0.45 \\
\hline ANB $\left({ }^{\circ}\right) \mathrm{NP}$ & $3.0(0.0-4.0)$ & $2.0(0.0-4.0)$ & 0.05 & $5.0(4.5-9.0)$ & $6.0(4.5-10.5)$ & 0.26 & $5.0(4.5-8.0)$ & $5.0(4.5-7.0)$ & 0.31 \\
\hline SN/GoGN $\left({ }^{\circ}\right) \mathrm{P}$ & $27.41 \pm 5.12$ & $27.53 \pm 4.47$ & 0.91 & $33.01 \pm 6.90$ & $31.96 \pm 5.79$ & 0.53 & $28.61 \pm 4.03$ & $24.84 \pm 5.57$ & 0.025 \\
\hline SN/PP $\left({ }^{\circ}\right) \mathrm{P}$ & $8.99 \pm 3.75$ & $9.21 \pm 2.96$ & 0.78 & $9.00 \pm 3.75$ & $9.98 \pm 3.40$ & 0.30 & $9.08 \pm 3.88$ & $8.81 \pm 3.23$ & 0.82 \\
\hline N-ANS $(\mathrm{mm}) \mathrm{P}$ & $55.25 \pm 3.44$ & $58.08 \pm 2.91$ & 0.000 & $55.11 \pm 2.92$ & $60.18 \pm 3.01$ & 0.000 & $55.55 \pm 3.74$ & $57.78 \pm 2.24$ & 0.03 \\
\hline ANS-Gn (mm)NP & $61.25(43.0-78.0)$ & $69.0(58.0-78.0)$ & 0.000 & $65.05 \pm 5.22$ & $70.62 \pm 6.05$ & 0.000 & $62.52 \pm 5.45$ & $66.21 \pm 5.80$ & 0.055 \\
\hline PNS-SN (mm)P & $47.70 \pm 3.22$ & $49.91 \pm 2.81$ & 0.002 & $47.92 \pm 2.69$ & $51.32 \pm 3.10$ & 0.000 & $46.75(44.0-57.5)$ & $49.0(45.0-59.0)$ & 0.037 \\
\hline ANS-SN (mm)P & $55.29 \pm 3.52$ & $58.18 \pm 3.29$ & 0.000 & $55.79 \pm 2.91$ & $60.92 \pm 2.37$ & 0.000 & $55.75(50.5-63.0)$ & $58.0(54.0-61.0)$ & 0.034 \\
\hline Go-Gn (mm) P & $76.88 \pm 4.74$ & $81.73 \pm 4.61$ & 0.000 & $74.76 \pm 4.50$ & $79.40 \pm 3.87$ & 0.000 & $77.75 \pm 5.51$ & $81.03 \pm 3.73$ & 0.040 \\
\hline S-Go $(\mathrm{mm}) \mathrm{NP}$ & $82.75(70.0-104.0)$ & $89.0(75.0-104.0)$ & 0.000 & $79.70 \pm 6.64$ & $89.66 \pm 5.97$ & 0.000 & $81.75 \pm 5.93$ & $91.00 \pm 5.79$ & 0.000 \\
\hline
\end{tabular}

Bonferroni düzeltmesine göre (0.05/3=0.016), p<0.016 anlamlı kabul edildi. NP: nonparametrik, medyan (min-maks); P: parametrik, ortalama \pm standart sapma (SD)

sahip olduğu belirlendi. Tüm gruplarda, açısal ölçümlerde cinsiyetler arasında istatistiksel olarak önemli farklılık bulunmadı.
Cinsiyetlere göre grupların karşılaştırılması Tablo 2 ve 3'te gösterildi. Gruplar arasında her iki cinsiyette SNA, palatal düzlem (SN/PP), alt yüz yüksekliği (ANS-

Tablo 2. Erkeklerde gruplar arası ölçüm değerlerinin karşılaştırılması

\begin{tabular}{|c|c|c|c|c|c|c|c|}
\hline & Grup $1(n=31)$ & Grup 2 ( $n=25)$ & Grup $3(n=19)$ & p değeri & Grup 1-2 & Grup 1-3 & Grup 2-3 \\
\hline $\operatorname{SNA}\left({ }^{\circ}\right) \mathrm{P}$ & $80.52 \pm 3.45$ & $81.28 \pm 3.92$ & $81.37 \pm 3.64$ & 0.646 & - & - & - \\
\hline $\operatorname{SNB}\left({ }^{\circ}\right) \mathrm{P}$ & $78.15 \pm 3.56$ & $75.36 \pm 3.58$ & $76.39 \pm 3.85$ & 0.016 & 0.015 & 0.288 & 1.000 \\
\hline $\mathrm{ANB}\left({ }^{\circ}\right) \mathrm{NP}$ & $2.0(0.0-4.0)$ & $6.0(4.5-10.5)$ & $5.0(4.5-7.0)$ & 0.000 & 0.000 & 0.000 & 0.196 \\
\hline SN/GoGN $\left({ }^{\circ}\right) \mathrm{P}$ & $27.53 \pm 4.47$ & $31.96 \pm 5.79$ & $24.84 \pm 5.57$ & 0.000 & 0.007 & 0.244 & 0.000 \\
\hline $\mathrm{SN} / \mathrm{PP}\left({ }^{\circ}\right) \mathrm{P}$ & $9.21 \pm 2.96$ & $9.98 \pm 3.4$ & $8.81 \pm 3.23$ & 0.468 & - & - & - \\
\hline $\mathrm{N}-\mathrm{ANS}(\mathrm{mm}) \mathrm{P}$ & $58.08 \pm 2.91$ & $60.18 \pm 3.01$ & $57.78 \pm 2.24$ & 0.007 & 0.020 & 1.000 & 0.019 \\
\hline ANS-Gn(mm)NP & $69.0(58.0-78.0)$ & $71.0(58.0-83.0)$ & $65.0(55.0-77.0)$ & 0.069 & - & - & - \\
\hline PNS-SN(mm)NP & $49.5(44.5-55.0)$ & $51.0(46.5-58.5)$ & $49.0(45.0-59.0)$ & 0.209 & - & - & - \\
\hline ANS-SN( $\mathrm{mm}) \mathrm{NP}$ & $58.0(49.0-67.0)$ & $61.0(55.0-64.0)$ & $58.0(54.0-61.0)$ & 0.000 & 0.001 & 1.000 & 0.003 \\
\hline Go-Gn (mm) P & $81.73 \pm 4.61$ & $79.4 \pm 3.87$ & $81.03 \pm 3.73$ & 0.118 & - & - & - \\
\hline S-Go $(\mathrm{mm}) \mathrm{NP}$ & $89.0(75.0-104.0)$ & $90.0(76.5-102.5)$ & $89.0(83.0-100.0)$ & 0.872 & - & - & - \\
\hline
\end{tabular}

Bonferroni düzeltmesine göre (0.05/2=0.025), p<0.025 anlamlı kabul edildi. NP: nonparametrik, medyan (min-maks); P: parametrik, ortalama \pm standart sapma (SD)

Tablo 3. Kızlarda gruplar arası ölçüm değerlerinin karşılaştııılması

\begin{tabular}{|c|c|c|c|c|c|c|c|}
\hline & Grup 1( $n=56)$ & Grup $2(n=39)$ & Grup $3(n=18)$ & $\mathrm{p}$ değeri & Grup 1-2 & Grup 1-3 & Grup 2-3 \\
\hline SNA $\left({ }^{\circ}\right) \mathrm{P}$ & $80.23 \pm 3.55$ & $80.68 \pm 3.24$ & $82.58 \pm 2.32$ & 0.033 & & & \\
\hline $\operatorname{SNB}\left({ }^{\circ}\right) \mathrm{P}$ & $77.43 \pm 3.57$ & $75.14 \pm 3.59$ & $77.19 \pm 2.31$ & 0.005 & 0.005 & 1.000 & 0.111 \\
\hline ANB $\left({ }^{\circ}\right) N P$ & $3.0(0.0-4.0)$ & $5.0(4.5-9.0)$ & $5.0(4.5-8.0)$ & 0.000 & 0.000 & 0.000 & 0.879 \\
\hline SN/GoGN $\left({ }^{\circ}\right) P$ & $27.41 \pm 5.12$ & $33.01 \pm 6.90$ & $28.61 \pm 4.03$ & 0.000 & 0.000 & 1.000 & 0.022 \\
\hline SN/PP $\left({ }^{\circ}\right) P$ & $8.99 \pm 3.75$ & $9.00 \pm 3.75$ & $9.08 \pm 3.88$ & 0.996 & - & - & - \\
\hline N-ANS (mm)P & $55.25 \pm 3.44$ & $55.11 \pm 2.92$ & $55.55 \pm 3.74$ & 0.898 & - & - & - \\
\hline ANS-Gn (mm)NP & $61.25(43.0-78.0)$ & $66.0(54.0-76.0)$ & $63.0(52.5-70.5)$ & 0.050 & - & - & - \\
\hline PNS-SN (mm)NP & $48.0(41.0-57.0)$ & $48.0(41.5-55.0)$ & $46.75(44.0-57.5)$ & 0.897 & - & - & - \\
\hline ANS-SN (mm)NP & $55.25(48.0-64.0)$ & $56.0(49.0-62.0)$ & $55.75(50.50-63.0)$ & 0.794 & - & - & - \\
\hline Go-Gn (mm) P & $76.88 \pm 4.74$ & $74.76 \pm 4.50$ & $77.75 \pm 5.51$ & 0.043 & - & - & - \\
\hline S-Go $(\mathrm{mm}) \mathrm{NP}$ & $82.75(70.0-104.0)$ & $80.0(62.5-91.0)$ & $83.5(72.0-97.0)$ & 0.048 & - & - & - \\
\hline
\end{tabular}

Bonferroni düzeltmesine göre (0.05/2=0.025), p<0.025 anlamlı kabul edildi. NP: nonparametrik, medyan (min-maks); P: parametrik, ortalama \pm standart sapma (SD) 

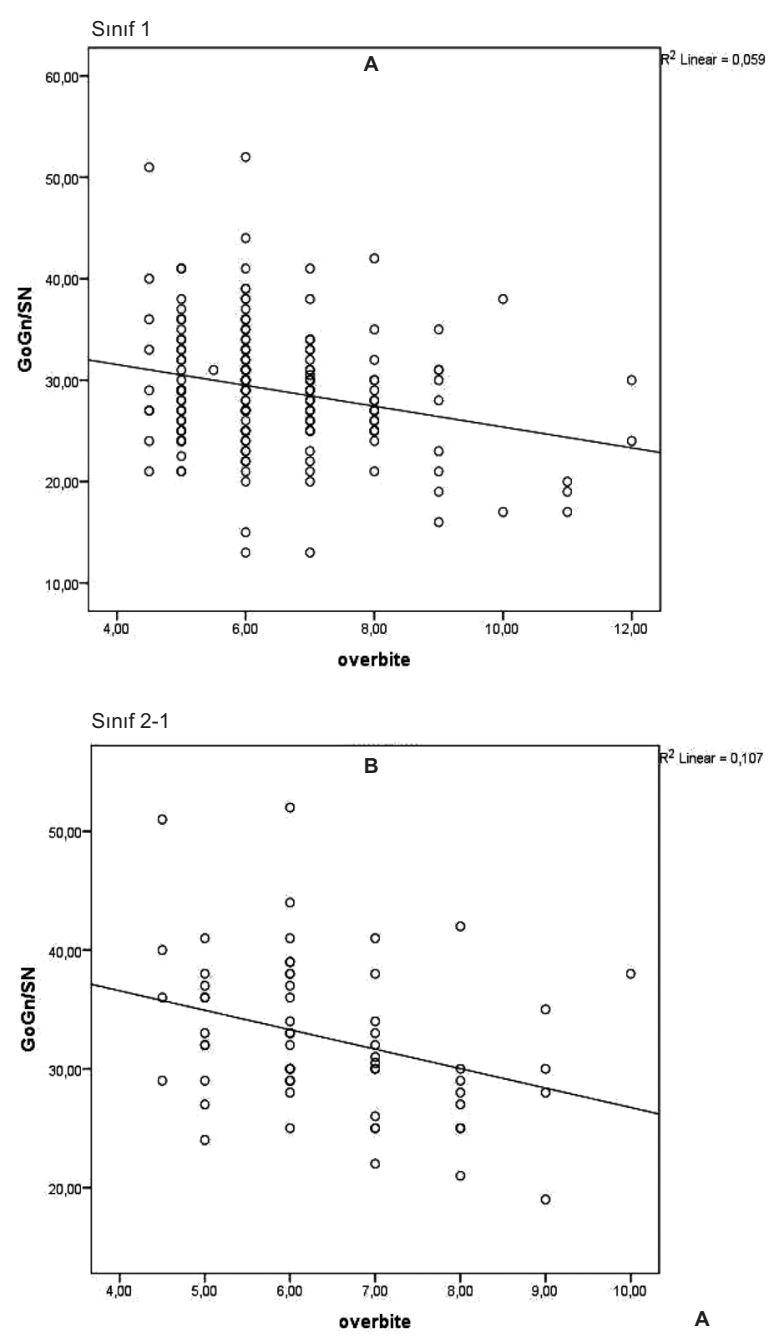

Şekil 2. SN/GoGn ve overbite korelasyon grafiği; A: Grup 1, B: Grup 2

Gn), arka yüz yüksekliği (S-Go), PNS-SN (mm) ve mandibular boyut (Go-Gn) değerleri bakımından fark saptanmadı. Buna karşılık her iki cinsiyette; SNB değerinin Grup 1 ve 2 arasında anlamlı farklılık gösterdiği ( $p<0.05$ ), SN/GoGn değerinin Grup 2'de Grup 1 ve 3'e göre anlamlı seviyede yüksek olduğu bulundu $(p<0.001)$.

Tüm gruplarda SN/GoGn ile overbite arasında negatif korelasyon saptandı (Şekil 2).

ANS-SN (mm) değeri ve üst yüz yüksekliğinin (NANS) yalnız erkeklerde Grup 2'de artmış olduğu ve Grup 1 ve Grup 3 ile anlamlı farklılık gösterdiği bulundu $(p<0.001$ ve $p<0.01$; Tablo 2$)$.

\section{TARTIŞMA}

Artmış overbite'ın kraniyofasiyal yapı ile ilişkisinin daha ayrıntılı değerlendirilebilmesine yönelik olarak bu çalışmada sagital yönde farklı iskeletsel yapıya sahip Sınıf 1 ve Sınıf 2 anomalili erişkin bireylerde artmış overbite ile is- keletsel yapı ilişkisi değerlendirildi ve cinsiyetlere göre karşılaştırıldı. Literatürde bu tip bir çalışmaya rastlanıımamıştır. Çalışma grubuna aktif büyüme ve gelişimi tamamlanmış bireyler dahil edildi. Pubertal atılım döneminde overbite miktarında bir azalma olduğu; bu azalmanın mandibular ramusun vertikal yön büyümesine ve mandibular büyük azılardaki erupsiyona bağlı gelişebildiği bildirilmektedir. ${ }^{11,15,26}$ Ayrıca büyüme döneminde büyük azı ve kesici dişlerin erupsiyonu da devam etmekte, ${ }^{19}$ özellikle ikinci büyük azı dişlerin sürmesi esnasında overbite azalmaktadır. ${ }^{21}$ Bu nedenlerle bu çalışmada daimi dişlenmenin tamamlandığı ve aktif büyüme gelişimin bittiği erişkin bireyler üzerinde overbite-kraniyofasiyal yapı ilişkisinin değerlendirilmesi tercih edildi.

Klinisyenlerin çalışmalarının birbirleriyle kıyaslanabilirliğinde standart parametrelerin kullanılması önemlidir. Bundan dolayı bu çalışmada rutin ortodonti analizlerinde kullanılan parametreler kullanıldı. ${ }^{27,28} \mathrm{Bu}$ hem klinisyenlere vakasını değerlendirme bakımından rehberlik yapabilecekken, akademik olarak da diğer çalışmalarla kıyaslamaların yapılabilmesine olanak sağlayacaktır.

Bu çalışmada sadece boyutsal ölçümlerde erkeklerin kızlardan önemli seviyede daha büyük değerlere sahip olması bazı çalışmalarla ${ }^{1,29,30}$ uyumluluk gösterirken, farklııık olmadığını bildiren çalışmalarla çelişmektedir. ${ }^{14,16}$ Bu farklılık, çalışma bireylerinin yaş ortalaması, etnik yapısı ve kullanılan parametrelere bağlı olabilir.

\section{Sagital iskeletsel parametreler}

Bu çalışmada, her üç malokluzyon grubu arasında maksillanın sagital yön konumu (SNA) bakımından önemli farklııık bulunmadı. Bu sonuç daha önceki bazı çalışmaların 16,19-21 sonuçlarını desteklerken; Sınıf II/2 malokluzyonda maksillanın daha ileride olduğunu bildiren çalışmalarla ${ }^{22,31}$ farklılık göstermektedir. Al-Khateeb ve ark.nın ${ }^{22}$ yaptıkları çalışmada, Sınıf II/1 ve Sınıf II/2'nin dental ve iskeletsel karakteristiğini Sınıf 1 bireylerle karşılaştırdıkları çalışmada her iki malokluzyonda da maksillanın prognatik olduğu bildirilmektedir. Bu çalışmanın sonuçlarının diğer çalışmalarla²2,31 uyuşmamasının nedeni; gruplama kriterlerinin farklı olmasından kaynaklanabilir.

Literatürde Sınıf II/2 malokluzyonlu bireylerde Sınıf I malokluzyona sahip bireylere kıyasla mandibulanın daha kısa ${ }^{16,19,23,31}$ ve geride ${ }^{20,21}$ konumlandığı bildirilmektedir. Retruzif konumdaki maksillar kesici dişlerin mandibular gelişimi kısıtlamasının bu duruma neden olabileceği belirtilmektedir. ${ }^{19}$ Farklı olarak bu çalışmada Grup 3 ile hem Grup 1 hem de Grup 2 arasında mandibula boyutu (Go-Gn) ve sagital yön konumu (SNB) bakımından farklılık saptanmadı. Bu çalışmada Sınıf 1 bireylere göre farklı çıkmamasının sebebi, grubun optimal bireylerden değil Sınıf 1 deepbite olgulardan oluşmasından kaynaklanabilir. Grup 2'de mandibulanın her iki cinsiyette Grup 1'e göre daha geride konumlandığı 
bulundu. Bu çalışmanın sonuçlarını destekler şekilde bazı araşıırmalarda ${ }^{10,32}$ da Sınıf II/1 ve Sınıf II/2 arasında mandibulanın morfolojisi bakımından hiçbir fark bulunamamıştır. Farklı olarak ise, Khateeb ve ark. ${ }^{22}$ Sınıf II/ 1 'de mandibulanın retrognatik ve Sınıf II/ 2'de ise normal konumda olduğunu bildirmektedir.

Bu çalışmada grupların oluşturulmasında intermaksillar ilişki dikkate alınarak, iskeletsel Sınıf 1 ve Sınıf 2 artmış overbite'a sahip bireyler araştırmaya dahil edildi. Dolayısıyla Sınıf 1 grubunun ANB değerinin Sınıf 2 gruplarından (Grup 2 ve 3) istatistiksel olarak anlamlı seviyede daha düşük bulunması beklenen bir sonuçtur. Diğer çalışmalarda sadece dişsel sınıflama dikkate alındığından, özellikle Sınıf II/2 bireylerin iskeletsel olarak Sınıf 1 ve Sınıf 2 yapıyı da kapsadığı, iskeletsel yapıda ayırım yapılmadığı dikkat çekmektedir., ${ }^{5,11,12,16,21} \mathrm{Bu}$ sebeple de, bu çalışmanın sonuçları, diğer araştırmalardan farklılık göstermektedir.

İtermaksillar ilişki bakımından Hitchcock ${ }^{33}$ Sınıf I, Sınıf II/1, ve Sınıf II/2 malokluzyonlu bireyler arasında istatistiksel olarak önemli farklılıklar olduğunu bildirirken; Brezniak ve ark. ${ }^{20}$ sagittal yönde çeneler arası ilişkinin Sinıf Il divizyon 2 bireylerle normal okluzyona sahip bireyler arasında farklılık göstermediğini vurgulamışlardır.

Bu çalışmada mandibular korpus uzunluğu (Go-Gn) gruplar arasında farklııı göstermemektedir. Karlsen ${ }^{14,16}$ ise aktif büyüme dönemindeki bireylerde yaptığı çalışmalarda mandibular korpusun Sınıf II/2 ve Sınıf II/1 derin kapanış gruplarında Sınıf 1 kontrol grubuna göre daha kısa olduğunu belirtmektedir. Bu çalışmada, mandibulanın büyümesinin tamamlandığı erişkin bireyler değerlendirilirken; diğer çalışmalarda ise çocuk ve adolesanların değerlendirilmiş olması çalışma bulgularındaki farkııı̆ın nedeni olabilir.

\section{Vertikal iskeletsel parametreler}

Literatürde yüz yükseklikleri ile overbite arasındaki ilişkinin değerlendirildiği çalışmalarda farklı sonuçların bildirildiği göze çarpmaktadır. ${ }^{5,34}$ Atherton ${ }^{34}$ üst yüz yüksekliğinin derin kapanış vakalarında artmış olduğunu belirtirken, Mete $^{12}$ normal bireylerle Sınıf 2 bölüm 2 maloklüzyonlu bireyler arasında üst yüz yüksekliği bakımından farkılıık olmadığını bildirmiştir. Farklı olarak Karlsen ${ }^{14}$ derin kapanışa sahip Sınıf 2 bölüm 1 maloklüzyonlu çocuk bireylerde ön yüz yüksekliği ve üst yüz yüksekliğinin Sınıf 1 bireylerden daha kısa olduğunu bulmuştur. Araştırmacıların genel olarak hemfikir olduğu ise derin kapanış ile birlikte alt yüz yüksekliğinin daha kısa olduğudur. 13,16,23,26

Artmış overbite'a sahip bireylerin değerlendirildiği bu çalışmada Grup 2'de her iki cinsiyette de istatistiksel olarak anlamlı olmasa da alt yüz yüksekliğinin diğer gruplara göre artmış olduğu bulundu.

Grup 2'de sadece erkeklerde üst ön yüz yüksekliğinin (N-ANS) artığı ve nasal düzlemin anterior kısmının aşağı eğimlendiği (ANS-SN) görülmektedir. Bu sonuç Moyers ve ark.nın ${ }^{35}$ bulgularılya uyumluluk göstermektedir.

Sınıf II bölüm 1 ile karşıllaştıııldığında bölüm 2 vakalarda alt anterior yüz yüksekliğinin azaldığı bildirilmektedir. ${ }^{22}$ Alt yüz yükseklikleri bakımından ise gruplar arasında fark gözlenmedi. Bu bulguların diğer çalışmaların $22,34,16,26$ bulgularıyla örtüşmemesi mevcut çalışmadaki tüm grupların artmış overbite'a sahip bireyleri içermesinden kaynaklanabilir.

Yapılan çalışmalarda derin kapanışlı bireylerde posterior yüz yüksekliğinin artmış ${ }^{13,20}$ olduğu, farklılığın olmadığı ${ }^{36}$ ve hatta azalmış ${ }^{12}$ olduğu şeklinde çelişkili bulgular bildirilmektedir. Bu çalışmada ise; posterior yüz yüksekliği bakımından (S-Go) gruplar arasında herhangi bir fark saptanmadı.

Bu araşıırmada overbite ile mandibular düzlem eğimi arasında negatif korelasyon olduğu bulundu. Grup 3'te overbite artışı, azalmış mandibular düzlem eğimi ile açılanabilir. Birçok çalışmada da mandibular düzlem eğiminin Sınıf II/2 olgularda azalmış olduğu bildirilmektedir. ${ }^{12,18-20}$ Literatürde Sınıf 2/2 ile normal overbite'a sahip Sınıf 1 bireyler arasında mandibular eğimi bakımından fark olmadığı bildirilmektedir. ${ }^{10,16,19,23}$ Bu çalışmada mandibular düzlem eğiminin Grup1 ve 3'te benzerlik gösterdiği; Grup 2'de ise farklılık göstererek arttığı göze çarpmaktadır.

Genel olarak bu çalışmanın bulguları, overbite-kraniofasiyal yapı ilişkisini değerlendiren diğer çalışmaların ${ }^{16,22,26,34}$ sonuçlarıyla gerek çalışma gruplarının oluşturulmasındaki farklılıklar, gerekse bireylerin yaş ortalaması ve etnik sebeplerden dolayı örtüşmemektedir. Bireysel varyasyonların geniş olmasından dolayı birey sayısının arttırılı̆̆ı ve optimal overbite'a sahip bireylerle de karşılaştırmaların yapıldığı daha ileri çalışmalara intiyaç duyulmaktadır.

\section{Sonuç}

Bu çalışmada kraniyofasiyal yapıların sagital ve vertikal yönde gruplar arasında gösterdikleri farklılıkların genel olarak erkek ve kızlarda benzer olduğu görüldü. Grup 1 ve 3'te kraniyofasiyal yapıların sagital ve vertikal yönde benzerlik gösterdiği bulunurken; Grup 2'de sagital yönde mandibulanın daha geride konumlandığı; vertikal yön boyutlarının ise artmış olduğu tespit edildi.

\section{TeŞeKKür Ve AnMA}

Bu çalışma 25-29 Ekim 2014 tarihinde Ankara'da düzenlenen 14. Uluslararası Türk Ortodonti Derneği Kongresinde poster olarak sunulmuştur: Uzuner FD, Işık Aslan B, Dinçer M. 'Artmış overbite'a sahip iskeletsel sınıf 1 ve 2 anomalili erişkin bireylerde kraniofasiyal morfoloji'.

Çıkar çatışması: Yazarlar bu çalışmayla ilgili herhangi bir çıkar çatışmalarının bulunmadığını bildirmişlerdir. 


\section{KAYNAKLAR}

1. Ceylan i, Eröz UB. The effects of overbite on the maxillary and mandibular morphology. Angle Orthod 2001;71:110-5.

2. Beckmann SH, Kuitert RB, Prahl-Andersen B, Segner D, The RP, Tuinzing DB. Alveolar and skeletal dimensions associated with overbite. Am J Orthod Dentofac Orthop 1998;113:443-52.

3. Pollard D, Akyalcin S, Wiltshire WA, Rody WJ Jr. Relapse of orthodontically corrected deepbites in accordance with growth pattern. Am J Orthod Dentofacial Orthop 2012;141:477-83.

4. Rübendüz M. Overbite, overjet ve Angle sınıflaması arasındaki ilişkilerin değerlendirilmesi. Türk Ortodonti Dergisi 2002;15:28-35.

5. Rübendüz M, Esenlik E. Derin kapanışlı bireylerin karakteristik yapı özellikleri ve erken dönem tedavi yaklaşımları. Türk Ortodonti Dergisi 2002;15:28-35.

6. Franchi L, Baccetti T, Giuntini V, Masucci C, Vangelisti A, Defraia E. Outcomes of two-phase orthodontic treatment of deepbite malocclusions. Angle Orthod 2011;81:945-52.

7. Arat $M$, Köklü $A$, Özdiler E, Rübendüz M, Erdoğan B. Craniofacial growth and skeletal maturation: a mixed longitudinal study. Eur J Orthod 2001;23:355-63.

8. Skieller V, Björk A, Linde-Hansen T. Prediction of mandibular growth rotation evaluated from a longitudinal implant sample. Am J Orthod 1984;86:359-70.

9. Nanda R. Correction of deep overbite in adults. Dent Clin North Am 1997;41:67-87.

10. Kale Varlık S, Onur Alpakan Ö, Türköz Ç. Deepbite correction with incisor intrusion in adults: a long-term cephalometric study. Am J Orthod Dentofacial Orthop 2013;144:414-9.

11. Baccetti T, Franchi L, McNamara JA Jr. Longitudinal growth changes in subjects with deepbite. Am J Orthod Dentofacial Orthop 2011;140:202-9.

12. Mete L. Angle Klas II Div 2 malokluzyonların morfolojisi ve derin kapanışın etiyolojisi. [tez]. Ankara: Ankara Üniversitesi; 2001.

13. Bratu DC, Bălan RA, Szuhanek CA, Pop SI, Bratu EA, Popa G. Craniofacial morphology in patients with Angle Class II division 2 malocclusion. Rom J Morphol Embryol 2014;55:909-13.

14. Karlsen AT. Craniofacial morphology in children with Angle Class II1 malocclusion with and without deepbite. Angle Orthod 1994;64:43746.

15. Giri BT, Jyothikiran H, Shivalinga BM, Sanju Somaiah MK. Cephalometric evaluation of dentoalveolar and morphological changes associated with overbite in maxilla and mandible in 13-18 year old adolescents. Int Journal of Contemporary Dentistry 2011;2:35-46.

16. Karlsen AT. Craniofacial characteristics in children with Angle Class II-2 malocclusion combined with extreme deep bite. Angle Orthod 1994;64:123-30.

17. Prakash $P$, Margolis HI. Dentocraniofacial relations in varying degrees of overbite. Am J Orthod 1952;38:657-73.

18. Richardson A. Skeletal factors in anterior open bite and deep overbite. Am J Orthod 1969;56:114-27.

19. Pancherz H, Zieber K, Hoyer B. Cephalometric characteristics of Class II division 1 and Class II division 2 malocclusions: a comparative study in children. Angle Orthod 1997;67:111-20.

20. Brezniak N, Arad A, Heller M, Dinbar A, Dinte A, Wasserstein A. Pathognomonic cephalometric characteristics of Angle Class II Division 2 malocclusion. Angle Orthod 2002;72:251-7.

21. Fischer-Brandies $H$, Fischer-Brandies E, König A. A cephalometric comparison between Angle Class II division 2 malocclusion and normal occlusion in adults. Br J Orthod 1985;12:158-62.

22. Al-Khateeb EA, Al-Khateeb SN. Anteroposterior and vertical components of Class II division 1 and division 2 malocclusion. Angle Orthod 2009;79:859-66.

23. Godiawala RN, Joshi MR. A cephalometric comparison between Class II, division 2 malocclusion and normal occlusion. Angle Orthod 1974;44:262-7.
24. Baccetti T, Franchi L, McNamara JA. The cervical vertebral maturation (CVM) method for the assessment of optimal treatment timing in dentofacial orthopedics. Semin Orthod 2005;11:119-29.

25. British Standard Institue Glossary of Dental Terms. BS 4492. London, UK: British Standards Institution; 1983. p.114.

26. Wylie WL. The relationship between ramus height, dental height and overbite. Am J Orthod Oral Surg 1946;32:57-67.

27. Steiner CC. Cephalometrics for you and me. Am J Orthod 1953;39:729-55.

28. Burstone CJ, James RB, Legan H, Murphy GA, Norton LA. Cephalometrics for orthognathic surgery. J Oral Surg 1978;36:269-77.

29. Baloş Tuncer B, Tuncer C, Ulusoy Ç, İşcan HN. İdeal okluzyonlu genç Türk erişkin sefalometrik normlarının Burstone normları ile karşılaştırılması. AÜ Diş Hek Fak Derg 2007;34:77-84.

30. Marques LS, Armond MC, Ramos-Jorge ML, Vieira de Andrade RG, Bolognese AM. Correlations between dentoskeletal variables and deep bite in Class II Division 1 individuals. Braz Oral Res 2011;25:5662.

31. Blair ES. A cephalometric roentgenographic appraisal of the skeletal morphology of Class I, Class II division 1, and Class II division 2 malocclusions. Angle Orthod 1954;24:106-19.

32. Schudy FF. The control of vertical overbite in clinical orthodontics. Angle Orthod 1968;38:19-39.

33. Hitchcock HP. A cephalometric distinction of Class II division 2 malocclusion. Am J Orthod 1976;69:447-54.

34. Atherton JD. The influence of the face height upon the incisor occlusion and lip posture. Dent Pract Dent Rec 1965;15:227-31.

35. Moyers RE, Riolo ML, Guire KE, Wainright RL, Bookstein FL. Differential diagnosis of Class II malocclusions. Part 1. Facial types associated with Class II malocclusions. Am J Orthod 1980;78:477-94.

36. Nanda SK. Patterns of vertical growth in the face. Am J Orthod 1998;93:103-16.

\section{Evaluation of skeletal class 1 and 2 anomaly with increased overbite in adults; part 1: craniofacial morphology}

\section{AbStRACt}

OBJective: To evaluate the craniofacial morphology in adults having skeletal Class 1 and 2 anomaly combined with increased overbite, and compare gender differences among these subjects.

Materials and Method: Pretreatment cephalograms of 188 orthodontic patients (75 male, 113 female) with increased overbite $(\geq 4.5 \mathrm{~mm})$ between 16 and 45 years of age were evaluated. Subjects were divided into 3 groups as: Group $1(\mathrm{n}=87)$ skeletal Class I subjects (ANB=0-4), Group 2 $(n=64)$ skeletal Class 2 (ANB>4.5) with Angle Class II/1 malocclusion and Group $3(n=37)$ skeletal Class 2 with Angle Class II/2 malocclusion. Groups were compared according to gender. Five angular and 8 linear measurements were done considering vertical and sagittal craniofacial characteristics. For statistical evaluations, Bonferroni-corrected ANOVA test, Mann-Whitney $U$ and Kruskal-Wallis tests were used. In addition, correlation coefficients between the overbite and GoGnSN were calculated. 
RESULTS: In groups 1 and 2, males had greater values than females in milimetric measurements. In both genders, significant differences were found in SNB values between Group 1 and 2, and SN/GoGn value was significantly higher in Group 2. There was negative correlation between SN/GoGn and overbite in all groups. The ANS-SN $(\mathrm{mm})$ values and the upper facial height values (N-ANS; $\mathrm{mm}$ ) were increased only in males in Group 2, and showed significant differences with Groups 1 and 3.
CONCLUSION: While evaluating the skeletal characteristics in sagittal and vertical directions, Groups 1 and 3 showed similarity; whereas in Group 2, a more distally positioned mandible and an increased vertical morphology were found.

KEYWORDS: Craniofacial morphology; increased overbite; malocclusion, angle class I; malocclusion, angle class II division 1; malocclusion, angle class II division 2 